\title{
CONTRIBUIÇÕES DE VIGOTSKI PARA A ANÁLISE DA CONSCIÊNCIA DE CLASSE
}

\author{
Melissa Rodrigues de Almeida \\ Claudia Barcelos de Moura Abreu" \\ João Henrique Rossler
}

\begin{abstract}
RESUMO. Este artigo analisa as contribuições do psicólogo soviético Vigotski (1896-1934) para a compreensão dos processos de formação da consciência de classe e da consciência individual, nos marcos do referencial teórico marxista. A investigação consistiu de uma pesquisa teórica que teve por base as obras de Vigotski e de outros autores do campo do marxismo. Foram abordados três processos, que se articulam: 1) a constituição social e o desenvolvimento da consciência individual; 2) a formação da consciência social a partir das relações sociais de produção; 3 ) o processo da consciência de classe da classe trabalhadora na relação com seu ser social. Verificou-se que Vigotski traz importantes subsídios para a compreensão do processo analisado, especialmente no que diz respeito às mediações necessárias para a constituição da consciência individual na relação com a consciência social. Com base nessas contribuições, foi possível compreender o movimento da consciência individual articulado à consciência de classe.
\end{abstract}

Palavras-chave: Consciência; consciência de classe; Vigotski.

\section{VIGOTSKI CONTRIBUTIONS FOR ANALYSIS OF CLASS CONSCIOUSNESS}

\begin{abstract}
The investigation consisted of a theoretical research based on the works of Vigotski and other Marxist authors. We discussed three articulated processes: 1) the social formation and the development of individual consciousness; 2) the formation of social consciousness from the social relations of production; 3) the process of the class consciousness of the working class in relation to his social being. It was found that Vigotski provides important insights to understanding the process under discussion, especially related to the necessary mediations involved in the formation of individual consciousness in relation to social consciousness. Based on these contributions, it was possible to understand the movement of individual consciousness articulated to the class consciousness.
\end{abstract}

Key words: Consciousness; class consciousness; Vigotski.

\section{CONTRIBUCIONES DE VIGOTSKI PARA ANÁLISIS DE CONCIENCIA DE CLASE}

RESUMEN. Este artículo examina los aportes del psicólogo soviético Vigotski (1896-1934) para la comprensión de los procesos de formación de la conciencia de clase y de la conciencia individual, en el marco del referencial teórico marxista. La investigación consistió en una búsqueda teórica que se basaba en los trabajos de Vigotski y otros autores del campo del marxismo. Hablamos de tres procesos que se articulan: 1) la formación social y el desarrollo de la conciencia individual, 2) la formación de la conciencia social desde las relaciones sociales de producción, 3) el proceso de conciencia de clase de la clase obrera en relación con su ser social. Se encontró que Vigotski proporciona pistas importantes para comprender el proceso estudiado, especialmente en lo referente a las mediaciones necesarias en la formación de la conciencia individual en relación con la conciencia social. Sobre la base de estas contribuciones, es posible comprender el movimiento de la conciencia individual articulada a la conciencia de clase.

Palabras-clave: Conciencia; conciencia de clase; Vigotski.

Em tempos de grande ofensiva ideológica, em que se anuncia a perda da centralidade, ou mesmo o fim das classes sociais e da própria história, faz-se necessário retomar o debate acerca do fundamento das

Mestre em Educação pela Universidade Federal do Paraná. Professora Assistente da Universidade Federal do Paraná, Brasil.

Il Doutor em Educação Escolar pela Universidade Estadual Paulista - UNESP. Professor Adjunto da Universidade Federal do Paraná, Brasil.

æ Doutora em Educação pela Pontifícia Universidade Católica de São Paulo. Professora Adjunto da Universidade Federal de São Paulo, Brasil. 
relações sociais capitalistas e reafirmar sua atualidade na constituição da consciência humana.

No atual momento histórico nossa sociedade continua dividida em classes sociais e antagônicas, que estão em luta ora disfarçada, ora aberta. O mecanismo de produção e distribuição da riqueza continua baseado na exploração do trabalho e na produção de mais-valia, concentrando-se e centralizando-se cada vez mais nas mãos da classe capitalista. De outro lado, a grande massa da população torna-se cada vez mais uma classe de expropriados dos meios de produção. Por isso é necessário estudar e conhecer essa classe, tanto quanto é imperioso analisar e compreender o indivíduo que nela se constitui e os processos que se encontram na mediação de sua constituição, de modo a contribuir para a organização de ações que busquem a sua superação e a construção de uma sociedade sem classes.

O presente artigo se insere nesse contexto de investigação e resultou de um estudo teórico que teve como objetivo analisar especificamente o processo de produção da consciência de classe da classe trabalhadora na relação com a formação da consciência individual, tomando-se como base o debate marxista e as contribuições de L. S. Vigotski (1896-1934), psicólogo soviético que tem sua produção teórica localizada no contexto de consolidação da Revolução Russa.

Uma vez que Vigotski não aprofunda diretamente os estudos sobre o objeto de nossa pesquisa, a abordagem do tema se deu pela busca, em sua obra, de elementos teóricos que pudessem mediar a compreensão desses processos, tomando como pressupostos a historicidade do ser humano e, por conseguinte, de sua consciência. Com base nisso, buscamos entender por meio de que processos e mediações se dá o movimento da consciência de classe da classe trabalhadora, em que a consciência social ideologizada incorporada pelo indivíduo pode transformar-se, neste indivíduo, em uma consciência de classe revolucionária.

Abordaremos, assim, três processos diretamente articulados: 1) a constituição social e o desenvolvimento da consciência individual; 2) a formação da consciência social a partir das relações sociais de produção; 3) o processo da consciência de classe da classe trabalhadora na relação com seu ser social. Para desenvolver essa análise serão abordadas as mediações necessárias a esses processos e sua relação com o desenvolvimento da consciência individual, passando pelo papel da linguagem, pelo sistema de conceitos, pelo autodomínio da conduta e seus motivos.

\section{A CONSTITUIÇÃO SOCIAL E O DESENVOLVIMENTO DA CONSCIÊNCIA INDIVIDUAL}

Para desenvolver nosso estudo, partimos da concepção de ser humano segundo a qual o homem, para produzir sua existência, realiza uma atividade prática vital - isto é, que produz e reproduz a vida tipicamente humana: o trabalho. Assim, o homem se define essencialmente pela produção social e histórica de seus meios de vida.

Os seres humanos produzem sua existência por meio de sua atividade social, ou seja, a partir das relações que estabelecem entre si e com a natureza e simultaneamente produzem certa consciência social que, desse modo, é ao mesmo tempo determinada pelo seu ser social e determinante desse próprio ser. Podemos entender a consciência social como os modos de pensar, sentir e agir dominantes em uma dada sociedade, por exemplo, as formas de explicação para suas relações, para os fatos e acontecimentos históricos, para os fenômenos da natureza, as formas de sentir-se diante de certas situações, bem como as formas de atribuir valor (positivo ou negativo) a tais pensamentos e sentimentos. A consciência social é, antes de qualquer coisa, um produto social, e desenvolve-se baseada na complexidade da produção material humana, no grau de desenvolvimento das forças produtivas e nas relações sociais de uma dada sociedade.

Tais pensamentos e sentimentos constitutivos da consciência social são produzidos e reproduzidos nas relações sociais, portanto preexistem a cada ser humano particular, apesar de apenas ganharem vida nos indivíduos concretos. Assim, a consciência individual se constitui pela apropriação e internalização da consciência social, por meio da mediação de um sistema de conceitos, na forma de modos de pensar, agir e sentir. Constitui-se, então, como expressão da consciência social, e é ao mesmo tempo em que nas relações sociais entre os indivíduos e suas consciências que se produz a consciência social. Nesse processo dialético, "a vertente individual se constrói como derivada e como secundária sobre a base do social e segundo seu exato modelo" (Vigotski, 1999, p. 82).

Cada indivíduo encontra, ao nascer, um sistema de conceitos já constituído, mas em constante movimento, que pode inclusive ser modificado por ele em suas relações. $\mathrm{O}$ sistema de conceitos é composto pela linguagem, que, ao abstrair, isolar, generalizar e analisar os objetos do real, produz a consciência da existência de um mundo externo objetivo e de um mundo interno subjetivo, bem como o pensar sobre 
ambos. Assim, a linguagem permite aos seres humanos operarem com a representação do real na consciência, isto é, a partir do reflexo psíquico consciente, sem que necessariamente haja uma relação direta e imediata com esse real no momento em que se pensa. Como diz Vigotski (2000b), tudo o que é pessoal ou intrapsicológico já foi antes social ou interpsicológico. Ao se apropriar da linguagem, os indivíduos apropriam-se também de formas sociais de ver, pensar, sentir e agir no mundo.

Conforme os postulados de Vigotski (2001), internalizamos o mundo mediado pelo sistema de conceitos produzido socialmente nas relações materiais entre os homens. Isso significa que nossas expressões, impressões e sensações objetivas, a partir das quais se constitui nossa concepção de mundo, são orientadas pelas mediações do outro e pelos significados atribuídos histórica e socialmente aos objetos e fenômenos.

Para o autor, toda a experiência do homem culto atual está representada, em relação à realidade externa e à realidade interna, em um determinado sistema de conceitos, que tem sua origem e seu desenvolvimento ligados à realidade que representa. Cada conceito contém o conjunto de suas relações, seu lugar no mundo (Vigotski, 1999). Pensar com base em conceitos significa, portanto, possuir uma determinada forma de pensar, resultante do desenvolvimento histórico do pensamento. Por meio da apropriação da linguagem e pelo desenvolvimento das funções psicológicas superiores (memória mediada, atenção voluntária, percepção categorial, pensamento por conceitos, etc.), apropriamo-nos dos modos de pensar, agir e sentir da sociedade. Internalizamos um determinado sistema de significações que ao serem apropriados pelos indivíduos adquirem um sentido pessoal.

O conceito é considerado um sistema psicológico complexo e sua formação não é imutável ou fossilizada. Sendo assim, entendemos que o sistema de conceitos é determinado pelas condições históricas de uma sociedade, que oferece uns e não outros problemas a serem comunicados, assimilados, entendidos e resolvidos. Assim o modo de produção e organização de cada sociedade terá papel fundamental no desenvolvimento dos sistemas de conceitos. Como as relações sociais são permeadas por contradições - no caso da sociedade capitalista, contradições de classe - os significados também o serão, já que são sociais. Passaremos agora à análise dessas contradições de classe na formação da consciência.

\section{A FORMAÇÃO DA CONSCIÊNCIA SOCIAL A PARTIR DAS RELAÇÕES SOCIAIS DE PRODUÇÃO}

Se a realidade social histórica é constituída de contradições, tais contradições podem emergir na consciência dos indivíduos. No caso da sociedade capitalista, em que se produz o objeto fundamental desse nosso estudo, destacamos como uma importante contradição aquela existente entre o capital e o trabalho, expressa na luta de classes. Essa contradição tem expressão tanto na atividade material humana quanto na produção de sua consciência.

Com a emergência e o desenvolvimento do capitalismo, as relações sociais e a propriedade privada dos meios de produção ganham contornos peculiares: por um lado, as relações capitalistas de produção produziram um desenvolvimento das forças produtivas nunca visto antes - da carroça ao trem-bala, da lamparina à microeletrônica, da baioneta à bomba atômica; por outro, todo esse desenvolvimento produzido socialmente não é apropriado por toda a humanidade, pois é propriedade privada de uma classe social e está subjugado ao processo econômico de produção e acumulação de valor, isto é, à reprodução ampliada do capital.

Assim, no que diz respeito à sua atividade prática, as classes sociais, embora partilhem de uma mesma relação, estão em polos opostos e têm interesses antagônicos. Essa relação de conflito - fundamentada na divisão social do trabalho, na propriedade privada dos meios de produção e nas relações de assalariamento - serve de base material para o processo de alienação. Mészáros (2006) afirma, com base na obra de Marx, que o conceito de alienação teria quatro dimensões fundamentais, a saber, a alienação do homem em relação à natureza, a si mesmo (a sua própria atividade), ao seu ser genérico (a seu ser como membro do gênero humano) e aos outros homens.

Assim, embora se expresse na consciência, a alienação não tem origem na consciência, mas na atividade material humana, fonte da consciência. A expressão da alienação na consciência nos remete à questão da ideologia.

Em uma sociedade de classes com interesses antagônicos, como é a sociedade capitalista, a consciência social ganha a forma de ideologia, constituindo-se como reflexo das relações sociais dominantes, ou ainda, das relações de dominação produzidas nessa sociedade (Marx \& Engels, 2007). Dessa forma, a consciência social constitui-se como a expressão em ideias, valores e normas, das relações materiais dominantes em uma sociedade. $\mathrm{Na}$ medida 
em que a classe dominante tem controle dos meios de produção e distribuição das ideias, tem o poder de transformar suas ideias particulares em ideias dominantes, ou seja, em universais abstratos: universais porque generalizam e estendem a todas as classes o conjunto de suas ideias particulares; e abstratos porque no real não existe uma única classe (Chauí, 1984).

Em outras palavras, a ideologia representa as relações materiais de classe concebidas como ideias, sendo a alienação terreno fértil para a universalização da ideologia. A alienação dá a base para a ideologia naturalizar determinada forma de pensar como a única; para universalizar e estabelecer uma visão parcial e distorcida da realidade, mas que corresponde às relações de dominação. Nesse sentido, Chauí (1984) diz que as ideias dominantes não são as únicas, mas tornam-se a maneira pela qual todos os membros da sociedade irão pensar, sentir e agir.

Assim, a ideologia, que, como toda ideia, tem sua base no próprio real, transforma-se em instrumento de dominação ao universalizar as ideias da classe dominante e colocá-las como autônomas em relação a esse real, servindo de base para construir um sistema teórico que camufla e justifica a dominação de classe.

Conforme o exposto, a consciência social produzida no contexto da alienação ganhará contornos peculiares. A concepção de mundo presente no sistema de conceitos, nos signos, na palavra, está impregnada das ideias dominantes (universais abstratos) do momento histórico e do local em que é produzida. Esses sistemas de conceitos, que compõem e estão presentes no universo ideológico (nos discursos dominantes) de uma época e lugar, fixam-se e assim constituem o que definimos há pouco como a consciência social.

Não obstante, transformar a consciência social não é simplesmente trocar as ideias dominantes por outras ideias, já que estas são frutos das relações materiais dominantes, e não apenas ideias. Há que transformar o próprio mundo material e suas relações para que se produzam novas concepções de mundo que deem origem a outros conceitos.

\section{O PROCESSO DA CONSCIÊNCIA DE CLASSE DA CLASSE TRABALHADORA NA RELAÇÃO COM SEU SER SOCIAL}

Ao longo da história, as mudanças das sociedades resultaram sempre de mudanças nas relações de produção social da vida entre seus membros; no entanto, essas mudanças não dependem simplesmente de uma intencionalidade deliberada ou vontade arbitrária do ser humano (Germer, 2006). As transformações são determinadas por dadas leis, e “(...) se o ser humano puder identificar com precisão as leis de desenvolvimento da sua sociedade, será capaz de promover o seu desenvolvimento deliberadamente, o que não significa arbitrariamente, pois está sujeito aos limites impostos por estas mesmas leis" (Germer, 2006, p. 5).

Projetos de uma classe social expressam um movimento real das contradições sociais e geram teorias do processo de trabalho e do conhecimento que podem resultar em projetos de transformação social. Para entender a transformação da consciência social burguesa - internalizada pelos indivíduos na sociedade capitalista como a sua concepção de mundo - em uma consciência revolucionária, é importante avaliar o movimento da consciência de classe. Consideramos a consciência de classe como a expressão do ser social da classe, aquela que corresponde a determinado lugar nas relações sociais de produção.

Lukács (2003) ${ }^{1}$, ao desenvolver uma análise histórica das consciências de classe, mostra o importante papel da consciência da classe burguesa na transformação social do feudalismo, bem como seus limites a partir do capitalismo estabelecido.

Levando em conta o caráter da consciência que a burguesia - por conta de sua posição na produção e dos interesses que determinam sua ação - pode desenvolver, o autor húngaro levanta o caráter distinto da consciência de classe do proletariado. Entende o proletariado como a classe que, nas relações sociais capitalistas, tem a possibilidade de desenvolver uma consciência revolucionária. Assim destaca que a consciência revolucionária não é o que pensam os indivíduos proletários, mas constitui-se como uma possibilidade objetiva (Lukács, 2003).

Como dissemos, a consciência de classe tem relação direta com o ser social da classe. Como seu ser social, a consciência da classe se define pelos diferentes momentos de seu movimento. Ao longo da história, podemos notar que a classe trabalhadora ora amolda-se à ordem do capital ora apresenta ações coletivas de resistência (às vezes mais, às vezes menos organizadas) e de busca pela superação dessa ordem.

\footnotetext{
O próprio autor faz posteriormente uma análise crítica de sua obra História e consciência de classe: estudos sobre a dialética marxista, publicada como Prefácio em 1967. Embora reconheça várias contribuições para o estudo no campo do marxismo, especialmente ao sistematizar o debate em curso na época, entende que o texto de 1922 tem alguns aspectos subjetivistas e não incorpora aspectos fundamentais da ontologia marxista. Ainda assim, entendemos que suas reflexões são úteis para fazer avançar o debate e o estudo de nosso objeto.
} 
Seu ser social não se coloca de forma homogênea na relação com o capital. Assim, a consciência de classe dos trabalhadores não se define exclusivamente pela consciência fragmentada e alienada do indivíduo isolado, tampouco pela consciência da classe como sujeito revolucionário pautado pela ação coletiva, mas sim, pelos movimentos que levam de um a outro (Iasi, 2006).

Por essa definição, tanto a consciência alienada como a consciência da alienação ou a consciência revolucionária expressam diferentes momentos do processo da consciência de classe, determinados por uma série de condições históricas.

No caso da classe trabalhadora, objeto de nosso interesse, a consciência de classe possui um movimento próprio relacionado ao movimento da produção capitalista. Isso ocorre porque o ser social da classe trabalhadora se constitui com uma contradição: ao mesmo tempo em que a força de trabalho, única mercadoria de que os trabalhadores dispõem para conseguir seus meios de vida, constitui-se como a parte variável do capital, os trabalhadores, como classe, suportam os ônus dessa sociedade, levando a processos de reação e luta contra esse sistema que os aliena da produção humana. O ser social da classe trabalhadora constitui-se, portanto, de uma classe que por sua própria natureza está integrada ao capital e volta-se contra esse capital. É uma classe do capital que deve ir além do capital, eliminando a si própria como classe para poder produzir uma transformação qualitativa da realidade social; e é nesse complexo processo que se forjam os sujeitos capazes de realizar essa transformação e emancipar a humanidade, superando o abismo existente entre a produção do ser genérico e sua apropriação pelos indivíduos. Não obstante, é tão somente se conduzida de forma coletiva, organizada e consciente que essa ruptura torna-se possível.

Iasi (2006) retoma as conceituações marxistas de classe em si e classe para si, afirmando que a classe em si define-se por ser determinada por suas relações com as outras classes, enquanto a classe para si, além de ser uma classe do capital, reconhece-se como tal, ou seja, possui "autoconsciência". Assim, coloca-se à classe trabalhadora ao mesmo tempo a possibilidade de saber que vende a sua força de trabalho e produz valor, mas também que pode interromper o processo de produção de mais-valia.

Destarte, e o domínio do capital quem cria objetivamente a classe em si e que coloca a massa da população em condições iguais; já a classe para si é o movimento de resistência e luta política criado pela própria classe trabalhadora em movimento. Não obstante, ter alcançado a posição de classe para si não quer dizer que o proletariado permaneça organizado na luta política. Há dois movimentos em jogo: um refere-se ao fato de essa classe ter-se colocado como autônoma pela primeira vez no movimento histórico; e o outro, ao fato de ela reconquistar essa posição em diferentes momentos, em busca da superação das relações capitalistas. Junto a esses movimentos há o processo de constituição da consciência dos indivíduos pertencentes à classe que se colocam em ação junto com ela. No próximo tópico buscaremos desenvolver essa relação.

\section{O MOVIMENTO DA CONSCIÊNCIA INDIVIDUAL NA RELAÇÃ̃ COM A CONSCIÊNCIA DE CLASSE}

Tendo como fundamento a internalização da concepção de mundo pela consciência individual, Vigotski (1999) afirma que a personalidade se forma com base em sistemas sociais internalizados e que “(...) os traços sociais e de classe formam-se no homem a partir de sistemas interiorizados, que nada mais são do que os sistemas e relações sociais entre pessoas trasladados para a personalidade" (p. 133). Uma sociedade dividida em classes, por conta do modo como se organiza para e no trabalho, determina que cada indivíduo vivencie, experiencie, se expresse, se exercite, se identifique apenas com uma dada parte do todo social. Isto produz as condições materiais para que esses homens, simultânea e contraditoriamente, distingam-se entre si sem deixarem de ser semelhantes, já que estão todos sob a regência das mesmas relações sociais. Assim, a divisão do trabalho em toda a sua extensão (econômica, política, cultural, etc.) é a base social do processo de formação de cada indivíduo singular (Palangana, 2002).

Não podemos esquecer, por outro lado, que as relações sociais e a realidade são movidas por contradições. Ao trasladarem-se para a pessoa, os sistemas sociais compostos por contradições internalizam-se como sistemas psicológicos em luta. Vigotski (2000a) chama de drama ao choque de sistemas em luta, característico da dinâmica da personalidade.

O drama é entendido como um conjunto múltiplo e contraditório de relações que se estabelece na vida social de cada pessoa e constitui-se de um choque de hierarquias divergentes entre funções vivenciadas pela pessoa nas suas diferentes relações (Vigotski, 2000a; Melo, 2001).

A inserção da pessoa em novos contextos e relações permite que, por meio de novas 
internalizações, enunciados, conceitos, normas e regras antes aceitos possam entrar em choque com essa nova realidade, a partir da percepção e da vivência de novos papéis sociais. $O$ avanço da vivência subjetiva desses conflitos na forma de drama para a consciência revolucionária dependerá de alguns fatores, entre os quais destacaremos a seguir a necessidade de um sistema de conceitos desenvolvido.

$\mathrm{Na}$ formação do sistema de conceitos que mobilizam as dimensões afetiva e cognitiva aparecem dois movimentos em unidade. $\mathrm{O}$ primeiro movimento desenvolve os conceitos espontâneos, que resultam do aprendizado espontâneo a partir da experiência pessoal e imediata. Vigotski (2001) aponta que os conceitos espontâneos servem à atividade cotidiana, mas caracterizam-se pela ausência de um sistema, o que leva ao sincretismo, à justaposição e insensibilidade, à contradição ${ }^{2}$.

Para que a pessoa possa confrontar ideias anteriormente internalizadas como sua concepção de mundo com novas ideias produzidas em novos contextos e percebê-las como ideias que se contradizem, é necessário que a vivência das contradições da realidade seja acompanhada do desenvolvimento de um segundo tipo de movimento dos conceitos, o qual desenvolve os conceitos científicos $^{3}$, situados em um sistema geral hierarquizado e que produzem a consciência reflexiva.

É necessário que o indivíduo comece a desenvolver um sistema de conceitos com base na apropriação de conceitos científicos e na ascendência dos conceitos espontâneos.

No desenvolvimento da consciência individual alienada, fundamentada nas relações sociais alienadas e alienantes, predominam os conceitos espontâneos. Isso se deve a que o desenvolvimento dos conceitos espontâneos está apoiado na espontaneidade da vida cotidiana, que dá origem a uma forma cotidiana de consciência. Segundo Rossler (2004a; 2006), baseado na teoria da vida cotidiana de Heller, o psiquismo

2 Para aprofundamento nas implicações do espontaneísmo da vida cotidiana na constituição do psiquismo ver Rossler (2004a).

3 Os conceitos científicos podem ser entendidos como um tipo de conceito não cotidiano ou não espontâneo, porém não o único. Pode haver os conceitos religiosos, que também exigem graus de abstração, e um sistema hierarquizado, por exemplo. Não entraremos nesse momento no debate da questão da ciência como ideologia, embora se saiba que a ciência, bem como as demais ideias produzidas na sociedade capitalista, possui uma perspectiva de classe e se presta à humanização ou a alienação. Como diz Löwy (1987), "A realidade social, como toda realidade, é infinita. Toda ciência implica opção” ( p. 195). cotidiano fundado na vida cotidiana tem como características a espontaneidade, o economicismo, o pragmatismo, a probabilidade, a confiança e fé, a ultrageneralização, a imitação e a entonação. Tais características constituem as formas cognitivas, afetivas e comportamentais do indivíduo na vida cotidiana e configuram o psiquismo cotidiano. Por si mesmas, essas características não são um problema, já que são necessárias à reprodução da sua vida; todavia, em uma sociedade de classes o psiquismo cotidiano torna-se mais suscetível ao processo de alienação e ao desenvolvimento de uma consciência alienada; porém a consciência fragmentada e alienada pode começar a perceber as contradições da realidade em movimento. Em razão dos mecanismos ideológicos, essa contradição pode ser vivida individualmente, tal como destacado anteriormente.

No movimento da consciência de classe, alguns fatores podem ser determinantes na passagem de uma consciência alienada para uma consciência da alienação. É importante ressaltar que essa superação da consciência alienada sempre ocorre de forma parcial e limitada, já que a alienação da consciência decorre da alienação do trabalho. Um desses fatores já foi apontado acima: o desenvolvimento de um sistema de conceitos organizado e hierarquizado, que busque apreender a realidade para além de sua aparência, percebendo suas relações, conexões e contradições.

Outro aspecto é destacado por Iasi (2006) ao afirmar que uma importante condição para a passagem a uma nova forma de consciência de classe do proletariado é a superação da vivência do conflito como algo individual (drama) por meio do grupo, isto é, por meio de um processo de identificação com o outro que pode levar a superação da vivência do conflito de forma apenas subjetiva. Ao perceberem a contradição existente em si, presente também no outro, os indivíduos veem a possibilidade de juntos conquistarem algo que lhes falta. Assim, em processos coletivos de luta essa passagem pode ficar potencializada.

A consciência de classe em si se produz no movimento das relações capitalistas articulado à ação da classe, quando os indivíduos vivenciam certas contradições não mais apenas em um âmbito subjetivo (característico da consciência alienada), mas ainda de uma forma espontânea. Nesse momento o sistema de significações que serve de mediação na consciência individual indica um movimento dos conceitos espontâneos aos conceitos científicos. Por sua vez, a consciência de classe para si é o nível da ação autoconsciente (autodeterminada), quando a classe trabalhadora desenvolve uma ação consciente de seus 
objetivos e de seus motivos, mediada por um sistema de conceitos. Na consciência em si está colocado um limite para o avanço e a conquista não só das reivindicações, mas da emancipação humana, que é a manutenção das relações sociais capitalistas, porque ainda se está no campo da espontaneidade. Ao se colocar como classe em si, o proletariado nega o capitalismo e ao mesmo tempo o afirma, pois a ação relacionada a essa consciência não consegue ir além do modo capitalista de produção.

A consciência para si surge da emergência da classe como sujeito; é um salto em direção à ação autoconsciente da classe. Caracteriza-se por ser uma consciência em que o proletariado, além de se perceber como classe na relação com outra classe, coloca-se em movimento na busca da superação das relações capitalistas e, mais do que isso, da abolição das classes. Essa forma de consciência pode ser chamada também de consciência revolucionária, pois surge da constatação de que a sociedade precisa ser transformada radicalmente para superar as condições de alienação e exploração (Iasi, 2006).

Para que a classe tenha produzido essa percepção, foi necessário colocar-se como classe para si na luta política contra o capital e a partir disso desenvolver uma teoria que levasse ao conhecimento do real para além de sua aparência.

A consciência, de modo geral, surge da relação sujeito-objeto, portanto é sempre produção de saber, de conhecimento. A consciência de classe para si é produto da ação política da classe trabalhadora e se constitui como uma consciência que impulsiona a ação revolucionária. Tem sua origem na ação da classe e passa a orientar essa ação, modificando-a qualitativamente, pois à medida que se conhece melhor a realidade, melhor se organiza a ação para intervir nessa realidade.

Para eleger o que deve vir a ser dentre as possibilidades do movimento do real é preciso conhecer as alternativas daquilo que pode vir a ser. Esse processo de conhecer ocorre mediado pelos conceitos, pela linguagem. Quando mediado por conceitos espontâneos, o conhecimento tem um grau de generalização mais imediato, é mais permeável à ideologia, à tradição, à ultrageneralização. Para romper com modos de pensar, agir e sentir cotidianos é necessário superar os conceitos espontâneos e desenvolver os conceitos científicos. Com isso se produz a consciência reflexiva e o controle deliberado sobre as próprias funções psicológicas, que permitem um distanciamento da realidade (externa e interna) para avaliá-la.
Vemos aqui possíveis contribuições de Vigotski no que se refere à formação da consciência de classe pelas mediações da atividade humana, quando o autor afirma que se chega ao "para si" quando se é capaz de ter autodomínio sobre a conduta e de inserir intencionalmente signos para mediar sua atividade psicológica. O domínio da conduta é conseguido pelo domínio dos meios que influenciam a conduta, sendo que o motivo desempenha papel fundamental em qualquer conduta humana.

O motivo é produto de um sistema complexo de estímulos que age no processo de eleição volitiva. A luta entre motivos está presente no processo de escolha, pois a pessoa consegue dominar sua conduta a partir da eleição de um motivo. No processo volitivo, um estímulo mais forte pode se transformar em um motivo débil, e vive-versa.

Parece-nos relevante que no processo de consciência de classe haja um ato volitivo que eleja certos motivos e não outros como meios em sua ação. Para Vigotski (2000b), o livre-arbítrio não consiste em estar livre de motivos, mas em tomar consciência da situação e da necessidade de eleger entre diferentes motivos. Ao dominar os meios que influem sobre nós (especialmente os signos), é que passamos a dominar os processos psicológicos, quando a vontade desenvolvida pela escolha passa a constituir a atividade humana.

Se para intervir na realidade (externa ou interna) é necessário conhecê-la; e se em grande parte a humanidade está alienada do conhecimento produzido socialmente, por este ser propriedade privada de uma classe, podemos concluir que os processos de livre escolha sob o capitalismo ficam bastante comprometidos. Sob relações capitalistas, o autodomínio será sempre limitado pela alienação material, que só se rompe pela transformação do modo de produção social da vida. Não podemos esquecer que, enquanto perduram as relações capitalistas, a consciência social universalizada será burguesa e a consciência de classe revolucionária funcionará, no máximo, como contraideologia. Uma nova consciência social só pode ser fruto de um novo ser social, baseado em novas relações.

Ainda assim, a tomada de consciência surge como um importante elemento para o processo de consciência de classe, por ser entendida como uma relação ativa de compreensão ou conhecimento do meio social. Demanda uma consonância entre fatos internos ou externos ao sujeito e sua representação na palavra, mesmo que inconclusa ou imperfeita (Toassa, 2006). Na sociedade capitalista, a tomada de consciência deve passar pelo entendimento de que a 
sociedade é dividida em classes com interesses antagônicos, pelo entendimento do movimento dessa sociedade provocado por suas contradições e ainda pelo entendimento de quais são as possibilidades de intervir nesse movimento.

Não obstante, o processo da consciência não é linear ou regular e pode, assim, em qualquer dos momentos de seu movimento, avançar ou retroceder a outras formas de consciência. Isso significa que, mesmo depois que um indivíduo (ou mesmo um grupo social) alcance a compreensão da alienação e desenvolva uma consciência revolucionária, outras condições podem fazer com que ele se amolde novamente à realidade alienada e retroceda a uma consciência alienada. Um importante fator para que isso ocorra é o fato de que, até o momento, em nenhuma das oportunidades históricas produzidas pelo desenvolvimento do capital e construídas pelo proletariado para a superação da sociedade de classes foi possível sustentar uma sociedade sem classes. $^{4}$

É importante ressaltar neste momento o duplo papel que a educação pode cumprir na sociedade burguesa: por um lado, o de adaptar os indivíduos às relações existentes - claramente hegemônicas sob o contexto da alienação; e por outro, o de servir como instrumento de luta pela superação da sociedade capitalista. Conforme Rossler (2004b), a educação cumpre papel fundamental na formação da consciência revolucionária, por apontar as limitações ideológicas das relações burguesas e a necessidade de superar essas relações, e por contribuir para a organização da classe revolucionária e para a apropriação de conhecimentos científicos e filosóficos que permitam compreender as leis que regem a realidade histórica e social, como forma de melhor intervir nessa realidade.

Outro aspecto interessante na relação da consciência de classe com a consciência individual diz respeito à realização (ou não) do projeto de transformação social pelo indivíduo. Para a superação das relações sociais capitalistas é necessária uma ação organizada e intencional da classe revolucionária; no entanto, o tempo de transição de um modo de produção a outro é, sem dúvida, maior que o tempo de uma geração, ou maior que o tempo de vida de um indivíduo singular (Iasi, 2007).

Isso quer dizer que, diante da compreensão do alcance da tarefa de transformação da sociedade, o

4 Foge aos objetivos deste estudo avaliar as determinações e causas para que isso ocorresse, mas o fato é que o modo de produção capitalista é ainda hegemônico mundialmente e não foi superado. indivíduo necessita transcender sua ação individual. É somente ao relacionar, nos termos de Leontiev (1978), a sua ação individual com a atividade da classe, que a pessoa torna-se capaz de perceber que seu projeto transcende sua existência individual e que a única forma de dar continuidade a esse projeto é inserir-se no projeto histórico e na atividade organizada da sua classe.

Assim, o movimento da consciência de classe e o da consciência revolucionária levam a pessoa a reorganizar sua conduta, sua atividade e seu sistema de conceitos de acordo com novos parâmetros. Vigotski (1999), ao tratar da reorganização dos sistemas psicológicos, remete-se a Spinoza e destaca que o homem pode “(...) criar um centro único para todo o sistema. (...) existem pessoas, cuja vida é um modelo de subordinação a um fim, que mostraram na prática que isso é possível" (p. 134).

Pensamos que a consciência de classe revolucionária possa se constituir como um centro único que reorienta a conduta e a consciência do indivíduo. Neste sentido, ainda que o indivíduo, por sua necessidade de sobrevivência, não possa abrir mão da atividade de reprodução da sociedade e ser parte constitutiva do capital, passa a subordinar sua conduta e sua consciência a esse centro. Com isso, faz com que nessa e em outras atividades apareça, mais ou menos, um sentido transformador ou de organização coletiva para a transformação.

Vigotski (n.d.), em seu texto A transformação socialista do homem, levanta três fontes fundamentais para a transformação da personalidade humana: 1) a libertação do homem pela destruição das formas capitalistas de produção e organização e das formas de vida social advindas dessa organização; 2) a libertação do potencial existente na grande indústria, colocandoo a serviço do desenvolvimento humano e não da acumulação de capital; 3) a mudança nas relações entre as pessoas e, por conseguinte, nas ideias, padrões e gostos, isto é, uma mudança totalizante do comportamento humano.

Entendemos, não obstante, que enquanto imperarem relações de alienação é necessário que haja uma busca ativa por sua superação e pela emancipação humana. Sob as relações alienadas, a meta de superação da alienação e de transformação individual e da sociedade depende de os indivíduos poderem e quererem buscar as máximas possibilidades existentes para a construção de uma hierarquia individual consciente das atividades cotidianas, mediada pela sua relação consciente com as objetivações genéricas para si (Duarte, 1993). 


\section{CONSIDERAÇÕES FINAIS}

Como vimos, a consciência da classe trabalhadora se constitui como expressão de seu ser social. É a consciência de ocupar um determinado lugar nas relações sociais que leva à possibilidade de agir conforme essa consciência. Esse lugar não é estático, já que o ser da classe trabalhadora se constitui no movimento produzido pela contradição de estar integrada ao capital, como parte constitutiva, e ao mesmo tempo suportar o ônus dessa relação. Dessa forma, dependendo do momento do movimento da classe para o qual se olhe, ela aparece alienada e amoldada à ordem ou reivindicando direitos do capital, ou ainda tomando as rédeas de sua história e produzindo o salto qualitativo necessário à superação do capitalismo.

Esse movimento relaciona-se a outro processo, no qual também interfere, qual seja, o da formação da consciência individual. Embora a consciência de classe não possa ser considerada a soma da consciência dos indivíduos que compõem a classe trabalhadora, mas como uma síntese produzida por seu ser social, tal consciência somente se realiza objetivamente nos próprios indivíduos por seus modos de pensar, sentir e agir, os quais constituem sua concepção de mundo.

As classes sociais produzem maneiras de pensar relativas à sua posição na sociedade e à forma como apreendem o mundo de sua perspectiva. É com base no seu poder de dominação, material e intelectual, que a classe dominante faz com que sua perspectiva se generalize e se universalize. A partir disso, compreendemos como os indivíduos da classe trabalhadora, imersos em sua cotidianidade, apropriam-se espontaneamente, pela tradição e pela educação, de certos modos ideológicos de pensar, naturalizando-os; no entanto, a posição da classe trabalhadora no mirante das relações sociais lhe oferece um horizonte mais amplo e com isso a possibilidade de um maior alcance em sua visão e, assim, de captar aspectos das relações materiais que os colocam de frente com contradições importantes e fundamentais para o curso da história (Löwy, 1987).

Nesse sentido, a partir das contribuições de Vigotski ao campo da Psicologia, este estudo buscou avançar no entendimento de como a consciência alienada, fruto de relações sociais alienadas, pode tomar consciência de sua alienação e movimentar-se na direção de uma consciência revolucionária que vise à superação de tais relações; movimento que acreditamos - precisa ocorrer nas consciências individuais não de forma isolada, mas sim, necessariamente, na relação com o acúmulo teórico e prático produzido pela classe trabalhadora em sua trajetória histórica, sintetizado na consciência de classe.

No que diz respeito às condições subjetivas para a superação da alienação, coloca-se uma contradição: a consciência de classe, para se efetivar, deve estar em relação com a ação da classe, mas essa consciência só se realiza no indivíduo. Segundo Vigotski (1999), “(...) cada pessoa é em maior ou menor grau o modelo da sociedade, ou melhor, da classe a que pertence, já que nela se reflete a totalidade das relações sociais" (p. 368). Para Vigotski, o caráter de classe, a natureza de classe e as distinções de classe são responsáveis pela formação dos tipos humanos e as contradições internas dos sistemas sociais encontram sua expressão acabada no tipo de personalidade e na estrutura do psiquismo humano de cada período histórico (Vigotski, n.d.).

A partir disso, o autor soviético ressalta que "A fonte da degradação da personalidade das pessoas, na forma capitalista de produção, também contém, em-si mesma, o potencial para um infinito crescimento da personalidade humana." (Vigotski, s.n., p. 5).

Aqui, retomamos a ideia - já bastante exposta no decorrer de nosso trabalho - de que a consciência do indivíduo se forma de acordo com as relações sociais em que esteja inserido. Assim, transformando-se as relações sociais, transformam-se os modos de pensar, sentir e agir sintetizados na concepção de mundo, mudando de forma significativa a consciência humana, a qual por sua vez pode mudar a realidade.

O movimento de construção de uma nova sociedade exige um projeto que deve se delinear pelo movimento coletivo da classe trabalhadora. Vigotski se engaja nessa busca, inspirado também pelo momento histórico de ebulição revolucionária em que vive, e para tanto procede ao estudo da consciência, do desenvolvimento humano e de um homem novo.

Ao longo dessa nossa investigação, pudemos confirmar que Vigotski tem valiosas contribuições ao estudo da consciência de classe e de sua relação com a consciência individual. Mais do que nunca, devemos reafirmar a atualidade desse admirável psicólogo, suas proposições teóricas que tanto valorizam o processo de aprendizado sistemático e científico, em busca do desenvolvimento de um processo educativo que leve os indivíduos a apropriarem-se das máximas possibilidades conquistadas pelo gênero humano na explicação da realidade.

Sublinhamos, ainda, que sua obra é muito rica e certamente ficam ainda muitas possibilidades de caminhos a serem percorridos, e reconhecemos que 
existem outras questões que poderiam ter sido abordadas ou aprofundadas neste trabalho; no entanto, se o processo de conhecimento é também um movimento de aproximação da realidade, esperamos ter dado nossa contribuição ao nos aproximarmos um pouco mais do fenômeno aqui em causa e aberto novos debates.

Assim sendo, fechamos com as palavras de Vigotski (1999, p.417):

Ser donos da verdade sobre a pessoa e da própria pessoa é impossível enquanto a humanidade não for dona da verdade sobre a sociedade e da própria sociedade. Ao contrário, na nova sociedade nossa ciência se encontrará no centro da vida. 'O salto do reino da necessidade ao reino da liberdade' colocará inevitavelmente a questão do domínio de nosso próprio ser, de subordinálo a nós mesmos.

\section{REFERÊNCIAS}

Chauí, M. S. (1984). O que é ideologia. São Paulo: Abril Cultural, Brasiliense.

Duarte, N. (1993). A individualidade para-si: contribuição a uma teoria histórico-social da formação do indivíduo. Campinas, SP: Autores Associados.

Germer, C. M. (2006). As forças produtivas e a revolução social revisitadas. [CD-ROM]. In Anais do 11 Encontro Nacional de Economia Política, Vitória: Universidade Federal do Espírito Santo.

Iasi, M. L. (2006). As metamorfoses da consciência de classe: o PT entre a negação $e$ o consentimento. São Paulo: Expressão Popular.

Iasi, M. L. (2007). Ensaios sobre consciência e emancipação. São Paulo: Expressão Popular.

Leontiev, A. (1978). O desenvolvimento do psiquismo. Lisboa: Livros Horizonte.

Löwy, M. (1987). As aventuras de Karl Marx contra o Barão de Munchhausen: marxismo e positivismo na sociologia do conhecimento. São Paulo: Busca Vida.

Lukács, G. (2003). História e consciência de classe: estudos sobre a dialética marxista. São Paulo: Martins Fontes.
Marx, K. (2002). O 18 Brumário e Cartas a Kugelmann. (7a ed). Rio de Janeiro: Paz e Terra.

Marx, K.; Engels, F. (2007). A ideologia alemã. São Paulo: Boitempo.

Melo, D. M. (2001). A construção da subjetividade de mulheres assentadas pelo MST. Dissertação de Mestrado, Programa de Pós-Graduação em Educação. Universidade Estadual de Campinas, Campinas-SP.

Mészáros, I. (2006). A teoria da alienação em Marx. São Paulo: Boitempo.

Palangana, I. (2002). Individualidade: afirmação e negação na sociedade capitalista. São Paulo: Summus.

Rossler, J. H. (2004a). O desenvolvimento do psiquismo na vida cotidiana: aproximações entre a psicologia de Alexis N. Leontiev e a teoria da vida cotidiana de Agnes Heller. Caderno CEDES, 24(62), 100-116. Recuperado em 10 de abril, 2010, da SciELO (Scientific Eletrocnic Library On line): www.scielo.br

Rossler, J. H. (2004b). A educação como aliada da luta revolucionária pela superação da sociedade alienada. In Duarte, N. (org.), Crítica ao fetichismo da individualidade. (pp. 75-98) Campinas, SP: Autores Associados.

Rossler, J. H. (2006). Sedução e alienação no discurso construtivista. Campinas, SP: Autores Associados.

Toassa, G. (2006). Conceito de consciência em Vigotski. Psicologia USP, 17(2), 59-83. Recuperado em 10 de abril, 2010, da SciELO (Scientific Eletrocnic Library On line): www.scielo.br

Vigotski, L. S. (1999). Teoria e método em psicologia. (2a ed.). São Paulo: Martins Fontes.

Vigotski, L. S. (2000a). Manuscrito de 1929. Educação \& Sociedade, XXI(71), 21-44.

Vigotski, L. S. (2001). A construção do pensamento e da linguagem. São Paulo: Martins Fontes.

Vigotski, L. S. (s.n.) A transformação socialista do homem. Recuperado em 5 de janeiro, 2007, de www.pstu.org.br/cont/subjetividade_vigotski.doc

Vygotski, L. S. (2000b) Obras escogidas, v. III (2a ed). Madrid: Visor.

Recebido em 26/08/2010 Aceito em 13/11/2011
Endereço para correspondência:

Melissa Rodrigues de Almeida. Praça Santos Andrade, 50, sala 215, ala Alfredo Buffren, CEP 80060-240, Curitiba-PR. E-mail: melissa.r.almeida@gmail.com. 